\title{
Review \\ Radiomics in Lung Diseases Imaging: State-of-the-Art for Clinicians
}

\author{
Anne-Noëlle Frix ${ }^{1}$, François Cousin ${ }^{2}$, Turkey Refaee ${ }^{3,4}{ }^{\oplus}$, Fabio Bottari ${ }^{5}$, Akshayaa Vaidyanathan ${ }^{3,5}$, \\ Colin Desir ${ }^{6}$, Wim Vos ${ }^{5}$, Sean Walsh ${ }^{5}$, Mariaelena Occhipinti ${ }^{5}$, Pierre Lovinfosse ${ }^{2}$, Ralph T. H. Leijenaar ${ }^{5}$, \\ Roland Hustinx ${ }^{2}$, Paul Meunier ${ }^{6}$, Renaud Louis ${ }^{1}$, Philippe Lambin ${ }^{3}(\mathbb{D})$ and Julien Guiot ${ }^{1, *(1)}$
}

1 Department of Respiratory Medicine, University Hospital of Liège, 4000 Liège, Belgium; an.frix@chuliege.be (A.-N.F.); r.louis@chuliege.be (R.L.)

2 Department of Nuclear Medicine and Oncological Imaging, University Hospital of Liège, 4000 Liège, Belgium; fcousin@chuliege.be (F.C.); pierre.lovinfosse@chuliege.be (P.L.); rhustinx@chu.ulg.ac.be (R.H.)

3 The D-Lab, Department of Precision Medicine, GROW-School for Oncology, Maastricht University, 6229 Maastricht, The Netherlands; t.refaee@maastrichtuniversity.nl (T.R.); akshayaa.vaidyanathan@radiomics.bio (A.V.); philippe.lambin@maastrichtuniversity.nl (P.L.)

4 Department of Diagnostic Radiology, Faculty of Applied Sciences, Jazan University, Jazan 45142, Saudi Arabia

5 Research and Development, Radiomics, 4000 Liège, Belgium; fabio.bottari@radiomics.bio (F.B.); wim.vos@radiomics.bio (W.V.); sean.walsh@radiomics.bio (S.W.); mariaelena.occhipinti@radiomics.bio (M.O.); ralph.leijenaar@radiomics.bio (R.T.H.L.)

6 Department of Radiology, University Hospital of Liège, 4000 Liège, Belgium; Colin.Desir@chuliege.be (C.D.); Paul.meunier@chuliege.be (P.M.)

* Correspondence: j.guiot@chuliege.be; Tel.: +32-4-3663979

Citation: Frix, A.-N.; Cousin, F.; Refaee, T.; Bottari, F.; Vaidyanathan, A.; Desir, C.; Vos, W.; Walsh, S.; Occhipinti, M.; Lovinfosse, P.; et al. Radiomics in Lung Diseases Imaging: State-of-the-Art for Clinicians. J. Pers. Med. 2021, 11, 602. https://doi.org/ $10.3390 /$ jpm11070602

Received: 4 May 2021

Accepted: 21 June 2021

Published: 25 June 2021

Publisher's Note: MDPI stays neutral with regard to jurisdictional claims in published maps and institutional affiliations.

Copyright: (c) 2021 by the authors. Licensee MDPI, Basel, Switzerland. This article is an open access article distributed under the terms and conditions of the Creative Commons Attribution (CC BY) license (https:// creativecommons.org/licenses/by/ $4.0 /)$.
Abstract: Artificial intelligence (AI) has increasingly been serving the field of radiology over the last 50 years. As modern medicine is evolving towards precision medicine, offering personalized patient care and treatment, the requirement for robust imaging biomarkers has gradually increased. Radiomics, a specific method generating high-throughput extraction of a tremendous amount of quantitative imaging data using data-characterization algorithms, has shown great potential in individuating imaging biomarkers. Radiomic analysis can be implemented through the following two methods: hand-crafted radiomic features extraction or deep learning algorithm. Its application in lung diseases can be used in clinical decision support systems, regarding its ability to develop descriptive and predictive models in many respiratory pathologies. The aim of this article is to review the recent literature on the topic, and briefly summarize the interest of radiomics in chest Computed Tomography (CT) and its pertinence in the field of pulmonary diseases, from a clinician's perspective.

Keywords: radiomics; artificial intelligence; lung diseases; precision medicine

\section{Introduction}

Described as the "high-throughput extraction of large amounts of image features from radiographic images" [1], radiomics is the subject of much research. This quantitative instrument is beginning to establish itself as a recognized imaging biomarker and paraclinical tool, serving both the fields of diagnosis and prognosis, along with predicting or monitoring response to treatment. The aim of radiomics is to extract quantitative, actionable information from standard-of-care medical images (computed tomography (CT), magnetic resonance imaging (MRI), positron emission tomography (PET), etc.), which are not easily visible or quantifiable with the naked eye, in order to build a model assessing clinical outcomes, including diagnostic, prognostic or predictive perspectives, to precisely identify and describe a pathological entity.

The following two methods can be used to perform a radiomic analysis: hand-crafted feature processing, or deep learning (DL). Hand-crafted feature (e.g., texture, shape, intensity, wavelet) processing will afford information on a specific targeted area of the imaging 
modality, distinctively from other related data (e.g., clinical, biological, genomic, histological, or treatment-related data). Contrastingly, deep learning methods will proceed to an extensive data-driven approach, processing a huge amount of information on the model of a simplified neural brain network, and without needing prior image segmentation (Figure 1).

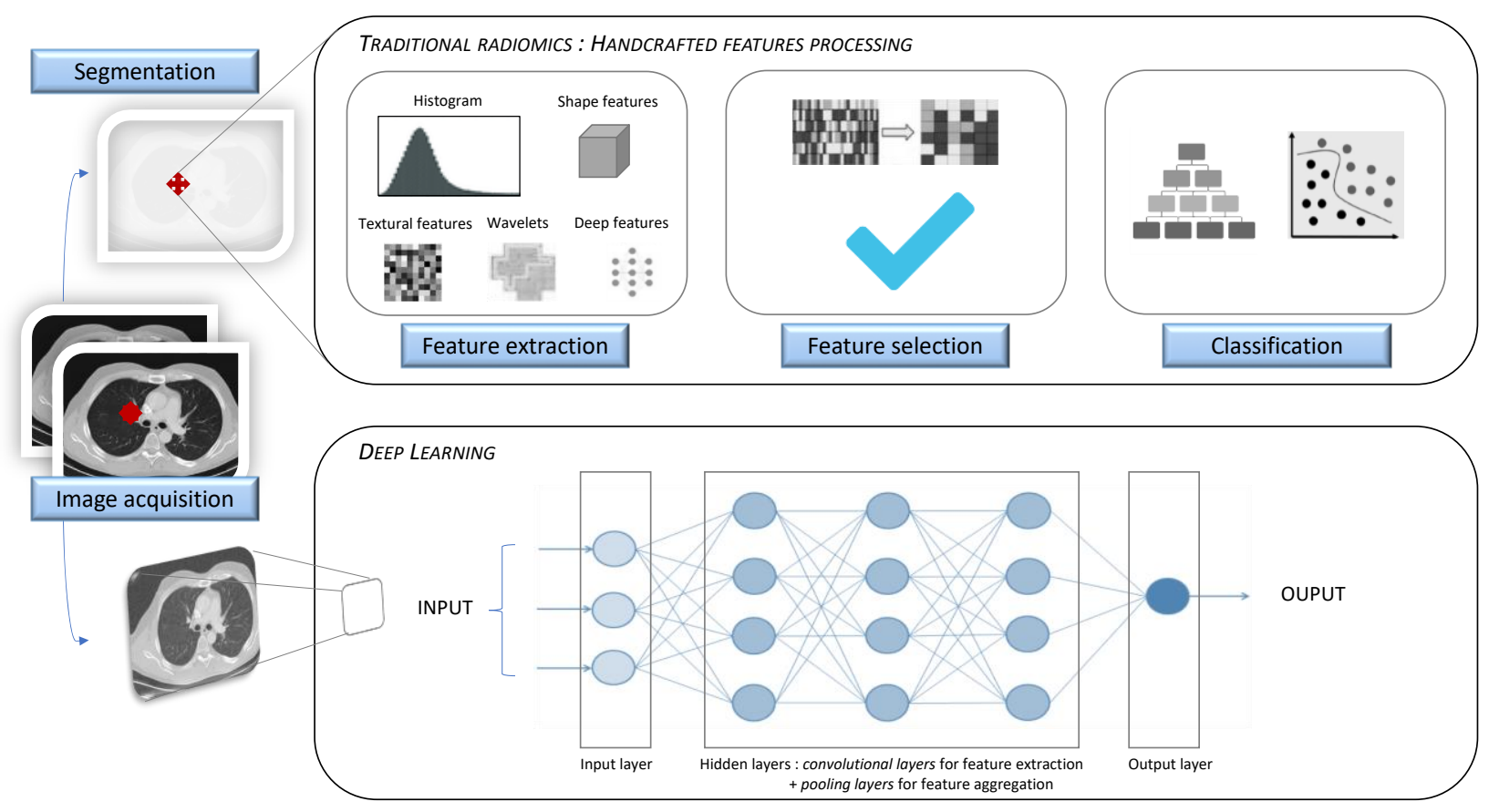

Figure 1. Traditional radiomics and deep learning approaches. Radiomic analysis workflow for handcrafted features (top) and deep learning method (bottom).

The basic concepts inherent to radiomics and artificial intelligence are displayed in Table 1. Some of these concepts will be repeatedly used in the following sections.

As a young and developing tool in medicine, radiomics is still facing challenges that are limiting its wide use in clinical practice. Those include technical artifacts (inadequacy between acquisition and reconstruction, and inaccuracy in preprocessing procedures such as in segmentation), the lack of standard criteria to establish the accuracy of the results in the training and validation processes, and limited real-world experience in assessing the impact of quantitative imaging on clinical outcomes and diagnostic algorithm. Despite these limiting factors, research in the field is extensive, and should possibly and gradually establish radiomics as a clinical tool of major importance.

Applied to lung diseases, quantitative $\mathrm{CT}$ analysis extracts features such as threshold, histogram, and morphologic and texture analysis, and produces a quantifiable and reproducible evaluation of parenchymal changes. Radiomics has been used in the fields of nodules and cancer, obstructive and restrictive diseases, and infiltrative diseases (including idiopathic pulmonary fibrosis (IPF), hypersensitivity pneumonitis, connective tissue-related interstitial lung disease and combined pulmonary fibrosis and emphysema (CPFE)).

The aim of this narrative review is to report the recent literature, and briefly summarize the interest of radiomics and Artificial intelligence (AI) in chest CT and their application in the field of pulmonary diseases, from a clinician's perspective. 
Table 1. AI and radiomics: basic concepts.

\section{Terminology Used in Radiomics and AI}

Artificial intelligence

Wide-ranging branch of computer science, generating complex software that perform tasks that would typically have required human intelligence, by sensing and responding to a feature of their environment.

Technology combining elements of artificial intelligence with radiological and pathology image processing. Its aim is to assist in the detection and/or diagnosis of diseases, improving the accuracy of radiologists with a reduction in time in the interpretation of images.

CAD (Computer Aided Detection or Diagnosis)

Method that extracts a large number of quantitative features from radiographic

Radiomics medical images using data-characterization algorithms, to help in disease diagnosis and prognosis.

Field in artificial intelligence studying computer algorithms that improve automatically through experience, by building a model based on sample data, known as "training data", in order to make predictions or decisions.

Supervised learning: The computer receives example inputs and their foreseen

Machine Learning outputs. Its goal is to learn a general and reproducible function that links inputs to outputs.

Unsupervised learning: The computer receives no labels to the learning algorithm for previously undetected patterns in a data set, leaving it on its own to find structure in its input.

Class of deep neural networks, which have the particularity of being fully

Convolutional neural networks connected networks. It gives them the advantage of understanding the hierarchical pattern in data and assembling more complex patterns using smaller and simpler patterns.

Voxel

Single sample, or data point, on a regularly spaced, three-dimensional grid. In CT scans, the values of voxels are Hounsfield units.

A voxel is a $3 \mathrm{D}$ pixel.

ROI (Region of Interest) Image areas containing the information relevant to image processing.

Measure of the asymmetry of attenuation distribution.

Skew of histogram

The lung normal attenuation histogram is skewed to the left.

There is a decreased leftward skewness in IPF.

Kurtosis of histogram

Measurement of how sharp an attenuation distribution curve is. Kurtosis is abnormally low in idiopathic pulmonary fibrosis (IPF).

Total count of pixels/voxels above or below a specific attenuation value that

Threshold measurement determines a relative volume.

Threshold measures in emphysema quantifies the extent of emphysema according to a specific index of -950 Hounsfield units (HU).

Texture analysis

Statistical methods that evaluate spatial relationship between voxels in an ROI, in order to characterize textural features of the parenchyma and give information about heterogeneity.

AI: Artificial Intelligence, CT: Computed Tomography, ROI: Region of Interest.

\section{The Role of Radiomics in Lung Diseases}

The application of radiomics in the field of lung diseases could lead to improvements in the clinical and paraclinical workflow in diagnosis, prognosis, management, follow-up and monitoring the response to treatment.

\subsection{Lung Nodules}

Lung nodules appearance provides a substantial clinical challenge, raising the question of diagnosis, prognosis and management. The detection of small nodules is known to be a difficult task. Indeed, the current diagnostic classification relies on size and growth rate as the main differentiators between benign and malignant nodules [2-4]. However, this 
approach is still imperfect and needs to be improved. Furthermore, the final diagnosis still relies on invasive biopsy.

Different research groups among the quantitative imaging network (QIN) [5] are currently developing radiomic models to describe nodules or tumors, based on size, shape, margins, texture and intensity. Their aim is to assess if the lesion is malignant or benign, and to determine its inherent prognosis, to evaluate its response to treatment and eventually to correlate imaging with genomics or histology. The application of artificial intelligence and radiomics in pulmonary nodule management is promising [6]. Studies of interest concerning radiomics and lung nodules are described in Table 2.

Diagnosis. Apart from differentiating lung cancer from benign pulmonary nodules, thanks to nodule-size evaluation and texture-based analysis, radiomic analysis also extends its perspective to histological sub-typing among the same lesion, linking it to genomic information, and subsequently revealing prognostic and response to treatment evaluations. Several radiomic signatures that are able to accurately classify lung nodules have been published. For example, Chen et al. [7] defined a four-features radiomic signature, displaying an $84 \%$ accuracy in lung nodule classification. Additionally, the use of volumetric software leads to a more accurate and quantitative nodule sizing. In the same field, studying the volume doubling time (VTD) can lead to a better assessment of nodule growth rate. For example, a nodule with a VTD higher than 400-600 days has a 4.1\% probability of malignancy, whereas a VTD lower than 400 days displays a malignancy probability of $9.7 \%$ [8]. Analysis of the NELSON trial results demonstrated that lung cancer mortality was significantly lower in high-risk patients who underwent volume CT screening (semi-automated extraction), than among those who underwent no screening [9]. Nodule texture can also be studied, empowering the accuracy with which radiomics can classify malignant and benign nodules. For example, Ma et al. [10] achieved an accuracy of $82.7 \%$, and Hawkins et al. [11] demonstrated an accuracy of $80.0 \%$. Other teams also reached relevant results [12,13]. Mao et al. [14] reported an overall accuracy of $89.8 \%$ in the qualitative diagnosis of small solitary pulmonary nodules (SSPNs), which outperformed the American College of Radiology (ACR) Lung-RADS approach [15]. Moreover, when texture analysis was combined to clinical and CT features, Lee et al. [16] demonstrated an improvement in the model performance (area under the curve, AUC), from 0.79 (clinical and CT features alone) to 0.93 (texture analysis incorporating clinical and CT features). Interestingly, there is a good concordance between the diagnostic abilities of radiomics software using ultra-low-dose chest CT compared to full-dose chest CT for lung nodule risk assessment, even if those are preliminary results [17]. Furthermore, Maldonado et al. [18] implemented and validated the BRODERS classifier (benign versus aggressive nodule evaluation using radiomic stratification), a high-resolution CT (HRCT)-based radiomic classifier in the characterization of indeterminate pulmonary nodules. Early works on convolutional neural networks (CNNs) compared to computer-aided detection/diagnosis (CAD) demonstrated a superiority of the radiomic approach in nodule classification, with a decrease in false positives, possibly reducing the need of several follow-ups [19-21]. Mehta et al. combined biomarkers, volumetric radiomics, and 3D CNNs to reach an algorithm classifying lung nodules [22]. Concerning histological subtyping, numerous studies have demonstrated the correlation between radiomic features and histology. For example, Wu et al. [23] described 53 radiomic features significantly associated with tumor histology, thus leading to an AUC of 0.72 in predicting the histological subtype. As discussed below (see "Section 2.2"), the possibility of radiomics to accurately predict the underlying gene expression of an identified tumor is also gathering considerable attention in recent years.

Prognosis. It has been shown that radiomic analysis performs well in the identification of nodules that are more at risk of evolution towards cancer. This has direct clinical implications, as it means shorter follow-up CT imaging and early detection of lung cancer. According to Digumarthy et al. [24], temporal changes in the radiomic features (process called delta-radiomics) of subsolid lung nodules indicates malignant etiology over benign. Indeed, they demonstrated that the radiomic features of benign nodules were stable over 
time, whereas the radiomic features of malignant nodules changed significantly between the baseline and follow-up CT, thus improving the accuracy up to $70.8 \%$ in the distinction between malignant and benign nodules with follow-up temporal changes.

One of the open questions that still remains is the sensitivity of quantitative imaging, and the correlation between imaging features computed with different segmentation algorithms. Indeed, segmentation algorithms ought to be highly reproducible, as the data extracted will serve for clinical purposes. Moreover, different segmentations might affect the radiomic features extraction. By performing a multicentric study based on a common set of reference images, Jayashree et al. [25] demonstrated a high correlation between groups of features (e.g., size and intensity features), whereas specific features within these groups did not correlate (e.g., reporting or not the size of airspaces within the lesion, affecting the mean intensity of the total nodule), uncovering subtle differences in the approach and calculations among the different centers. More research needs to be conducted to develop robust segmentation methods to provide accurate and reproducible nodule segmentation [26].

Table 2. Radiomics and lung nodules.

\begin{tabular}{|c|c|c|c|}
\hline Study & Description & Cohort & Performance \\
\hline Chen et al. (2018) [7] & $\begin{array}{l}\text { - } 750 \text { extracted features, among which } \\
\text { 76 relevant features were selected } \\
\text { - } \quad \text { 4-feature signature } \\
\text { - } \quad \text { Aim: nodule characterization }\end{array}$ & $\begin{array}{l}33 \text { benign } \mathrm{CT} \\
42 \text { malignant } \mathrm{CT}\end{array}$ & $\begin{array}{l}\text { Benign vs. malignant } \\
\text { Accuracy } 84 \% \\
\text { Sensitivity } 92.85 \% \\
\text { Specificity } 72.73 \%\end{array}$ \\
\hline $\begin{array}{l}\text { De Koning et al. (2020) } \\
\text { [9] }\end{array}$ & $\begin{array}{l}\text { - } \\
\text { 15,792 patients, divided into a } \\
\text { screening group (T0-T1 year-T2 } \\
\text { years-T3 years) and a no-screening } \\
\text { group } \\
\text { - } \quad \text { Follow-up of } 10 \text { years } \\
\text { - } \quad \text { Aim: nodule characterization through } \\
\text { volume and VTD }\end{array}$ & 15,792 patients & $\begin{array}{l}\text { Benign vs. malignant: impact on mortality } \\
\text { At } 10 \text { years, cancer mortality }=2.5 \\
\text { deaths } / 100,000 \text { persons } / \text { years (screening } \\
\text { group) vs. } 3.3 \text { deaths } / 100,000 \text { (no-screening } \\
\text { group) } \\
\text { Cumulative ratio } 0.76(p=0.01)\end{array}$ \\
\hline Ma et al. (2016) [10] & $\begin{array}{ll}\text { - } & 583 \text { extracted features } \\
\text { - } & \text { Random forest classifier } \\
\text { - } & \text { Aim: nodule characterization }\end{array}$ & $\begin{array}{l}36 \text { benign } \mathrm{CT} \\
94 \text { malignant } \mathrm{CT}\end{array}$ & $\begin{array}{l}\text { Benign vs. malignant } \\
\text { Accuracy } 82.7 \% \\
\text { Sensitivity } 80 \% \\
\text { Specificity } 85.5 \%\end{array}$ \\
\hline $\begin{array}{l}\text { Hawkins et al. (2016) } \\
\text { [11] }\end{array}$ & $\begin{array}{l}\text { - } 219 \text { extracted features, among which } \\
23 \text { showed concordance correlation }> \\
0.95 \\
\text { - } \quad \text { Aim: nodule characterization }\end{array}$ & $\begin{array}{l}328 \text { benign } \mathrm{CT} \\
170 \text { malignant } \mathrm{CT}\end{array}$ & $\begin{array}{l}\text { Benign vs. malignant } \\
\text { Accuracy } 80 \%\end{array}$ \\
\hline Huang et al. (2018) [12] & $\begin{array}{l}\text { - } \quad 1108 \text { extracted features } \\
\text { - } \quad \text { Aim: nodule characterization }\end{array}$ & $\begin{array}{l}\text { Training cohort } \\
70 \text { benign } \mathrm{CT} \\
70 \text { malignant } \mathrm{CT} \\
\text { Validation cohort } \\
26 \text { benign CT } \\
20 \text { malignant CT }\end{array}$ & $\begin{array}{l}\text { Benign vs. malignant } \\
\text { Accuracy } 91 \% \\
\text { Sensitivity } 95 \% \\
\text { Specificity } 88 \%\end{array}$ \\
\hline Uthoff et al. (2020) [13] & $\begin{array}{l}\text { - } \quad \begin{array}{l}\text { Extracted features from nodule and } \\
\text { perinodular parenchyma tissue }\end{array} \\
\text { - } \quad \text { Aim: nodule characterization }\end{array}$ & $\begin{array}{l}\text { Training cohort } \\
289 \text { benign CT } \\
74 \text { malignant CT } \\
\text { Validation cohort } \\
50 \text { benign CT } \\
50 \text { malignant CT }\end{array}$ & $\begin{array}{l}\text { Benign vs. malignant } \\
\text { Accuracy } 98 \% \\
\text { Sensitivity } 100 \% \\
\text { Specificity } 96 \%\end{array}$ \\
\hline Mao et al. (2019) [14] & $\begin{array}{l}\text { - } \quad 385 \text { extracted features } \\
\text { - } \quad \text { Comparison of radiomic model versus } \\
\text { model of ACR Lung-RADS } \\
\text { - } \quad \text { Aim: nodule characterization }\end{array}$ & $\begin{array}{l}\text { Training cohort } \\
156 \text { benign CT } \\
40 \text { malignant CT } \\
\text { Validation cohort } \\
75 \text { benign CT } \\
23 \text { malignant CT }\end{array}$ & $\begin{array}{l}\text { Benign vs. malignant } \\
\text { Accuracy } 89.8 \% \\
\text { Sensitivity } 81 \% \\
\text { Specificity } 92.2 \%\end{array}$ \\
\hline
\end{tabular}


Table 2. Cont.

\begin{tabular}{|c|c|c|c|}
\hline Study & Description & Cohort & Performance \\
\hline $\begin{array}{l}\text { Maldonado et al. (2021) } \\
\text { [18] }\end{array}$ & $\begin{array}{l}\text { - } \\
\text { - } \quad \text { Aim: to validate the BRODERS } \\
\text { classifier (benign versus aggressive } \\
\text { nodule evaluation using radiomic } \\
\text { stratification) as a HRCT-based } \\
\text { classifier for indeterminate } \\
\text { pulmonary nodules }\end{array}$ & $\begin{array}{l}\text { Validation cohort } \\
91 \text { malignant } \mathrm{CT} \\
79 \text { benign } \mathrm{CT}\end{array}$ & $\begin{array}{l}\text { Benign vs. malignant } \\
\text { AUC } 0.90 \\
\text { Sensitivity } 92.3 \% \\
\text { Specificity } 62 \%\end{array}$ \\
\hline
\end{tabular}

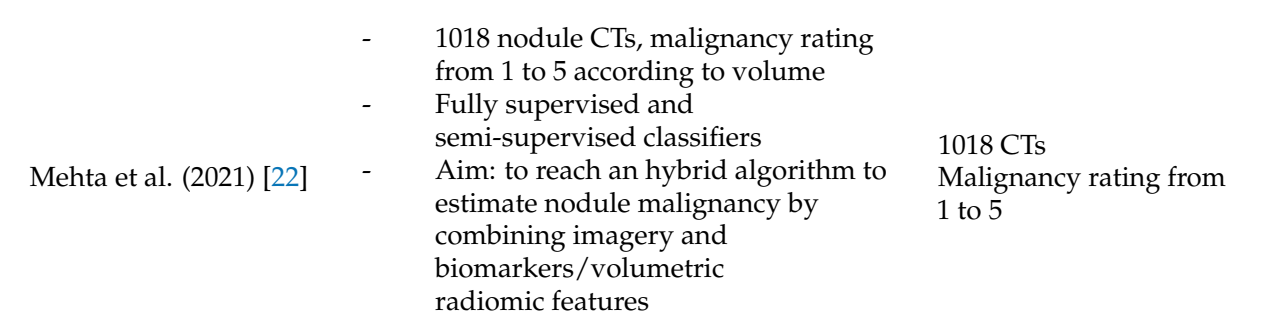

Benign vs. malignant AUC 0.87 on fully supervised 3D CNN + random forest model (images, biomarkers and volumetric features)

AUC 0.93 on semi-supervised random forest (biomarkers only)

$\begin{array}{lllll} & - & 92 \text { extracted features } & \\ \text { Digumarthy et al. } & - & 2 \text { significant features at baseline } & & \\ (2019)[24] & - & 52 \text { significant features at follow-up } & 31 \text { benign CT } & \text { Benign vs. malignant according to } \\ & - & \text { Aim: nodule characterization } & 77 \text { malignant CT } & \text { temporal changes } \\ \text { according to temporal changes } & & \text { AUC 0.741 }\end{array}$

\begin{tabular}{|c|c|c|c|c|}
\hline $\begin{array}{l}\text { Lee et al. } \\
\text { (2014) [16] }\end{array}$ & - & $\begin{array}{l}\text { Clinical, thin-section } \mathrm{CT} \text { and } \\
\text { texture features } \\
\text { Aim: prediction of transient vs. } \\
\text { persistent pattern of nodule }\end{array}$ & $\begin{array}{l}\text { Transient PSNs } \\
39 \text { benign CT } \\
\text { Persistent PSNs } \\
17 \text { benign CT } \\
30 \text { malignant CT }\end{array}$ & $\begin{array}{l}\text { Prediction of persistent part-solid nodules } \\
\text { AUC } 0.93 \text { if texture analysis was combined } \\
\text { to clinical and CT features }\end{array}$ \\
\hline $\begin{array}{l}\text { Autrusseau et al. (2021) } \\
\text { [17] }\end{array}$ & - & $\begin{array}{l}\text { >1000 extracted features } \\
\text { Aim: to compare quantitative and } \\
\text { qualitative concordance of pulmonary } \\
\text { nodule risk assessment by radiomic } \\
\text { software between full-dose (FD) chest } \\
\text { CT and ultra-low-dose (ULD) } \\
\text { chest CT }\end{array}$ & $\begin{array}{l}99 \text { lung nodules } \\
\text { - } \quad \text { FD chest CT } \\
\text { imaging } \\
\text { - } \quad \text { ULD chest CT } \\
\text { imaging }\end{array}$ & $\begin{array}{l}\text { Concordance between FD and ULD chest CT } \\
\text { in radiomic-guided nodule risk assessment } \\
\text { ICC of } 0.82 \text {, displaying a good agreement in } \\
\text { malignancy similarity index between ULD } \\
\text { and FD chest CT }\end{array}$ \\
\hline
\end{tabular}

CT: Computed Tomography, VTD: Volume Doubling Time, ACR: American College of Radiology, BRODERS: Benign versus aggRessive nODule Evaluation using Radiomic Stratification, HRCT: High Resolution Computed Tomography, AUC: Area under the Curve, CNN: Convolutional Nerual Network, ICC: Intraclass correlation coefficient, ULD: Ultra Low Dose, PSNs: Part-solid Nodules, FD: Full Dose.

\subsection{Cancer}

Lung cancer is still the leading cause of death among neoplastic diseases in men and women worldwide [27]. The National Lung Cancer Screening Trial (NLST) demonstrated that CT screening in current and ex-smokers provides a significant survival benefit $[28,29]$. As of today, biopsies are still needed to establish the diagnosis and status of tumors. Nevertheless, this procedure is invasive and only reflects the characteristics of the part of the tumor from which the sample was obtained, considering that some tumors can be anatomically heterogeneous. Due to technological advances in AI, radiomic analysis could be seen as a virtual biopsy tool, and could have the potential to diagnose and determine tumor phenotypes. Radiomics has been used to assess tumor phenotypes using various imaging modalities, such as CT, MRI and PET CT [30]. Studies of interest, concerning radiomics and lung cancer, are described in Table 3.

Diagnosis. Several studies have demonstrated the potential of radiomics in lung cancer diagnosis and staging [23,31-34]. Beyond anatomical characterization, radiomics could be used to predict the presence of particular mutations in genes. For example, Liu et al. and Zhang et al. $[35,36]$ established a correlation between CT radiomic features and EGFR 
(epidermal growth factor receptor) mutation, whereas Rios Velazquez et al. [37] created a radiomic model to classify mutations in pulmonary adenocarcinoma. Weiss et al. [38] assessed the potential of textural analysis to radiologically differentiate K-RAS mutations from pan-wildtype tumors, reaching an accuracy of $89.6 \%$. In the same perspective, Tang et al. [39] defined 12 robust radiomic features, generating an immune-pathology informed model to predict immune modulator status (interesting Cluster of differentiation 3 (CD3) and Programmed death-ligand 1 (PDL1)). Lastly, hypothesizing the fact that radiomics could provide histopathological analysis, while having the advantage of being non-invasive, Wu et al. [23] performed radiomic analysis to predict the histopathological types of non-small cell lung carcinoma (NSCLC), reaching a correlation with tumor histology of 0.72 (AUC). Additionally, another study demonstrated that separating ground-glass and solid CT radiomic features of part-solid nodules was useful in diagnosing the invasiveness of lung adenocarcinoma. Their radiomic model based on ground-glass and solid features yielded an AUC of 0.98 on the test data set, which was significantly higher than five other models tested (Brock University model, clinical semantic model, volumetric models, radiomic signature based solely on gross tumor volume (GTV) features, and perinodular features) [40].

Prognosis. Numerous studies corroborated the correlation between radiomic features and prognosis, in terms of the survival or occurrence of distant metastases [26,31,41-45]. For instance, Mattonen et al. [46] demonstrated the accuracy of radiomics to predict local recurrence in patients with early stage NSCLC, treated with stereotactic ablative radiotherapy. Their results also suggested that radiomics could detect early changes in the tumor, associated with local recurrence, which would not have been taken into account by clinicians.

Therapy. The use of radiomics to predict response to therapy was explored by several research groups, but has not yet been translated to clinical use [47,48]. Coroller et al. [49] studied pre-treatment radiomics data to determine if they could have predicted the response after neoadjuvant therapy in patients with locally advanced NSCLC. They found seven radiomic features that were predictive of residual disease (AUC > 0.6), and one radiomic feature that was predictive of a complete response (AUC 0.63). Similarly, Kim et al. [50] used radiomic analysis in combination with conventional clinical features to predict the response to tyrosine kinase inhibitors (TKI) in epidermal growth factor receptor (EGFR) mutant NSCLC, achieving a good predictive performance, with a concordance index of 0.77 .

Despite facing limitations inherent to its novelty (see "Section 3"), radiomics is seen as a revolutionary precision medicine approach in lung cancer. Its applications, as follow, in the field of research are broad and extensive: diagnosis, staging and prognosis, prediction of treatment response, and disease monitoring [51]. These characteristics are highly interesting, as lung cancer can face a rapid progression, but studies are still needed to reach real-life clinical application.

Table 3. Radiomics and lung cancer.

\begin{tabular}{|c|c|c|c|}
\hline Study & Description & Cohort & Performance \\
\hline Wu et al. (2016) [23] & $\begin{array}{l}\text { - } \quad 440 \text { extracted features } \\
\text { - } \quad 53 \text { features associated with } \\
\text { tumor histology } \\
\text { - } \quad \text { Aim: to predict cancer histopathology }\end{array}$ & $\begin{array}{l}\text { Training cohort } \\
198 \text { malignant CT } \\
\text { Validation cohort } \\
152 \text { malignant CT }\end{array}$ & $\begin{array}{l}\text { Tumor histology correlation } \\
\text { AUC } 0.72\end{array}$ \\
\hline Yu et al. (2019) [34] & $\begin{array}{l}\text { - } \quad 9 \text { relevant features selected } \\
\text { - } \quad \text { Aim: to diagnose and predict } \\
\text { pathologic stage in NSCLC }\end{array}$ & $\begin{array}{l}\text { Training cohort } \\
87 \text { NSCLC CT } \\
\text { Validation cohort } \\
58 \text { NSCLC CT }\end{array}$ & $\begin{array}{l}\text { Diagnosis and staging in NSCLC } \\
\text { AUC }>0.70 \text {, with predictive accuracy higher } \\
\text { in lung adenocarcinoma than in lung } \\
\text { squamous cell carcinoma }\end{array}$ \\
\hline
\end{tabular}


Table 3. Cont.

\begin{tabular}{cccc}
\hline Study & Description & Cohort & Performance \\
\hline
\end{tabular}

219 extracted radiomic features, among which 59 robust features

Liu et al. (2016) [36] were selected

- $\quad$ Aim: search for correlation with EGFR mutation status in adenocarcinomas
Prediction of mutation status

298 malignant CT AUC EGFR+ status prediction 0.647, improved to 0.709 when adding a clinical model

\section{6 relevant features selected}

Rios Velasquez et al. (2017) [37]
KRAS and EGFR mutation status

in adenocarcinomas
Training cohort

353 malignant CT

Validation cohort

352 malignant CT
Prediction of mutation status

AUC EGFR + versus EGFR - status 0.70

AUC KRAS + versus KRAS- status 0.63

AUC EGFR+ versus KRAS+ status 0.80

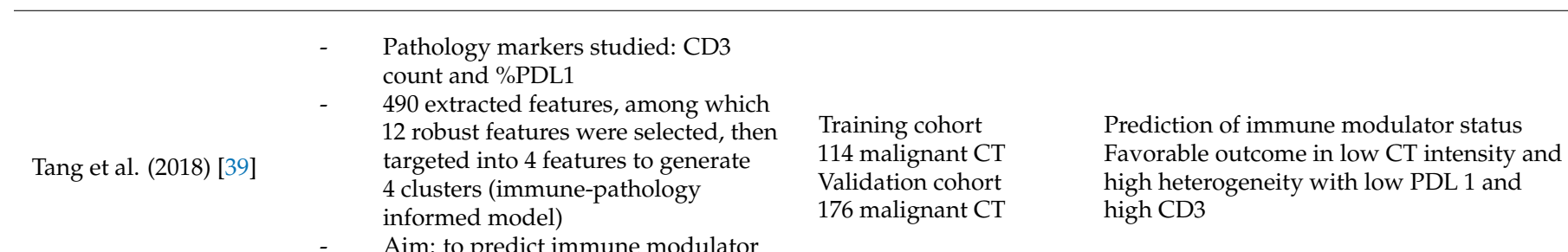

- Aim: to predict immune modulator status in NSCLC

Favorable outcome in low CT intensity and high CD3

\section{8 relevant features selected \\ - Comparison of radiomic models (ground-glass and solid features) with other models (Brock model, clinical semantic and volumetric models) Aim: to predict invasiveness of lung adenocarcinoma by using ground-glass and solid features from part-solid nodules}

Wu et al. (2020) [40]
Training cohort

229 NSCLC

Validation cohort

68 NSCLC
Prediction of invasiveness AUC 0.98 for the model combining ground-glass and solid features Improvement of 0.14 in AUC when adding ground-glass radiomic features to solid features
Coroller et al. (2015) [41]

- $\quad 445$ extracted features, among which 35 relevant features were selected

- $\quad$ Aim: to determine the capability of radiomic analysis to predict distant metastasis
Training cohort

98 malignant CT

Validation cohort

84 malignant CT
Prediction of distant metastasis A multivariate radiomic signature (3 features) yielded a high prognostic performance for distant metastasis (CI 0.61)

\begin{tabular}{|c|c|c|c|c|}
\hline He et al. (2019) [43] & - & $\begin{array}{l}519 \text { extracted features, among which } \\
35 \text { relevant features were selected } \\
\text { Aim: to predict lymph node } \\
\text { metastasis in resectable NSCLC }\end{array}$ & $\begin{array}{l}\text { Training cohort } \\
423 \text { NSCLC CT } \\
\text { Validation cohort } \\
294 \text { NSCLC CT }\end{array}$ & $\begin{array}{l}\text { Prediction of lymph node metastasis } \\
\text { Good discrimination for the model defining } \\
\text { a radiomics-based predictive score } \\
(\mathrm{C} \text { index } 0.785)\end{array}$ \\
\hline
\end{tabular}

2777 extracted features, among which
- $\quad 100$ most relevant features

Ferreira et al. (2018) [45] 100 most relevant features

- Aim: to predict lung cancer histopathology and metastases using machine learning models
Training cohort 52 malignant CT Validation cohort 16 malignant $\mathrm{CT}$
Histology and distant metastasis

AUC lymph nodal metastasis 0.89

AUC distant metastasis 0.97

AUC histopathology 0.92
104 extracted features, among which the 5 most relevant features were selected

Mattonen et al. (2016) [46]
Aim: to assess physicians' ability to detect local recurrence versus radiomic tool
182 malignant CT

Prediction of recurrence after SBRT AUC 0.85 (radiomic signature of 5 features predicting local recurrence) 
Table 3. Cont.

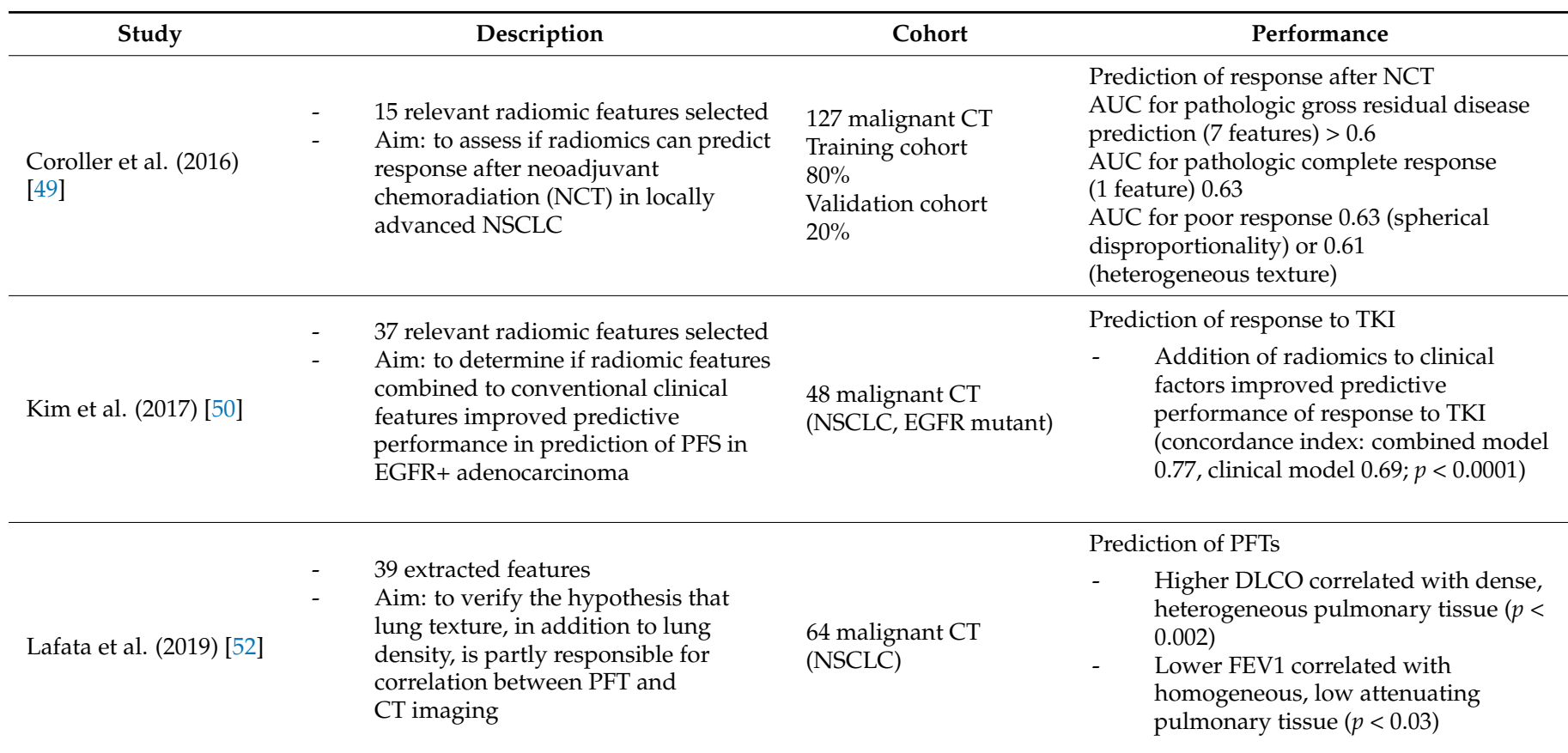

CT: Computed Tomography, NSCLC: Non-small cell lung cancer, AUC: Area under the curve, EGFR: epidermal growth factor receptor, KRAS: KRAS gene, CD3: Cluster of differentiation 3, PDL1: Programmed death-ligand 1, SBRT: Stereotactic body radiation therapy, TKI: Tyrosine kinase inhibitor, PFTs: Pulmonary function tests, DLCO: Diffusing capacity for carbon monoxide, FEV1: Forced Expiratory Volume.

\subsection{Obstructive Lung Diseases}

In current clinical practice, pulmonary function tests are crucial to assess the characteristics of obstructive lung diseases. However, while being useful in assessing respiratory performance, as well as volume and resistance ranges, they cannot inform the clinician about the local extent of emphysema or air trapping. Overcoming this anatomical deficiency, quantitative CT analysis can be used, and extensive research has been carried out to automate the quantification of emphysema or air trapping severity and distribution $[53,54]$, as well as to characterize airway diseases more precisely [55].

In this way, quantitative $\mathrm{CT}$ analysis and radiomics could be applied to various obstructive lung diseases, such as in the characterization of chronic obstructive pulmonary disease (COPD) or asthma, the detection of bronchiolitis obliterans, or even in planning eventual emphysema reduction therapy.

In obstructive pulmonary diseases, the lung texture and density are influenced by increased air abundance, compared to normal lungs. The origin of this excess of air plethora can be anatomical (emphysema) or functional (air trapping). In addition, the study of lung texture and density is highly biased by the respiratory phase [56]. During inspiration, the CT appearance of emphysema can be characterized by the following two methods: areas with a parenchyma density $<-950 \mathrm{HU}$ (emphysema index: percentage of parenchyma below attenuation threshold of $-950 \mathrm{HU}$ ) [57], or areas related to the lowest 15th percentile (emphysema index: lung voxels below threshold value in $\mathrm{HU}$, for which $15 \%$ of all lung voxels have a decreased attenuation value on the attenuation histogram) [58]. During expiration, air trapping can be defined as the area with a parenchyma density $<-856 \mathrm{HU}$ on expiratory CT. However, it might be difficult to differentiate low attenuation from air trapping versus low attenuation from emphysema. To address this issue, Pompe et al. [59] applied parametric response mapping (PRM), a method using a combination of thresholdbased measures taken simultaneously during inspiratory and expiratory phases on coregistered $\mathrm{CT}$, allowing a biphasic characterization of voxels.

Parallel to parenchyma characterization, quantitative analysis of airways can be realized up to the fifth bronchial generation. Quantitative CT metrics of airways include 
the study of wall thickness, area and density, and lumen diameter and area. However, its use faces a certain number of limitations, as airway metrics are highly influenced by lung volume, aging and inflammation [60]. Therefore, applying airway metrics in clinical practice is still at the preliminary stage.

\subsubsection{COPD}

Diagnosis. Applying radiomics could lead to better COPD characterization and quantification [61,62]. Lynch et al. [63] used an integrative description of the visual and quantitative evaluation of CT images in COPD to determine COPD phenotypes, and classified them into emphysema-predominant subtypes (six different subclassifications) and airwaypredominant subtypes (two subclassifications). Beyond the classical anatomical characterization, several research groups demonstrated the potential of $\mathrm{CT}$ radiomics features to correlate with lung function [52,64].

Prognosis. Cho et al. performed a radiomic analysis to predict survival and apply risk stratification in COPD, and reached a five-feature model displaying a C-index of 0.774 , accurately identifying patients with an increased risk of mortality [65]. Interestingly, CT vascular features can also be helpful in the characterization of COPD, as the quantitative assessment of pulmonary vascular alterations in COPD patients exhibited correlations with clinical parameters, such as pulmonary function tests (PFTs) and survival, in the The Korean Obstructive Lung Disease (KOLD) cohort [66].

Therapy. Quantitative CT analysis can also be used to assess the progression of emphysema in alpha-1-antitrypsin deficiency and the response to augmentation therapy [67]. Moreover, the assessment of lung lesions in emphysema, by CT quantification and perfusion scintigraphy, implements the best prediction of outcome in lung volume reduction (LVR) as a therapeutic option $[68,69]$.

\subsubsection{Asthma}

Asthma phenotyping is of utmost importance for disease categorization and personalized treatment. In this context, airway remodeling is seen as a possible imaging biomarker. Quantitative imaging led to the definition of asthma clusters, which were found to respond differently to the bronchodilator between the different imaging clusters [70]. Further characterization has been possible with the quantification of air trapping. For example, Choi et al. [71] found that four radiological clusters had differences in their response to high-dose inhaled corticosteroids (ICS). Quantitative CT analysis in asthma can also be used as a novel marker to predict or assess the response to treatment, which can lead to more personalized therapy [71,72].

\subsection{Interstitial Lung Diseases}

As a heterogeneous group of pathologically distinct processes, but sometimes radiologically overlapping entities, interstitial lung diseases (ILD) can represent a diagnostic challenge and face an unpredictable clinical course. Combined to biological data and PFTs, thin-section chest $\mathrm{CT}$ is essential in differentiating interstitial lung diseases, evaluating their severity and evolution over time, and possibly monitoring their response to therapy. Nevertheless, visual assessments of thin-section CT and traditional PFTs evaluation are relatively insensitive to slight changes or early disease. Moreover, visual evaluation of HRCT pattern is highly subjective and variable, even among experts. The finest analysis of specific radiological patterns, such as ground-glass opacities, honeycombing, traction bronchiectasis, attenuation and reticular density, and their volumetric distribution and spatial relationships, can lead to more precise diagnosis. Therefore, the contribution of radiomics, as a reproducible and accurate imaging tool, is a major issue. Some studies also reported a strong correlation between radiomic features in ILD and pulmonary function tests. Studies of interest, concerning radiomics and interstitial lung diseases, are described in Table 4. 
Diagnosis. Many studies have demonstrated the performance of quantitative CT analysis and its potential to assess the severity of ILD [73,74]. In IPF, Stefano et al. [75] demonstrated a strong correlation between radiological features and disease severity $(p=0.009)$. In scleroderma-related ILD, Martini et al. [76] used radiomics to detect ILD in sclerodermic patients and to predict their GAP (Gender, Age, Physiology) stage, as generally used in ILD evaluation (AUC 0.96). Many teams also determined correlations between quantitative radiological features and baseline PFTs $[77,78]$. One remaining recurrent matter of concern is the discernment between IPF and fibrosing non-specific interstitial pneumonia (NSIP). A recent study addressed this issue by using a CALIPER tool (computer-aided lung informatics for pathology evaluation and rating), combining PFTs and quantitative imaging to significantly discriminate NSIP from IPF [79]. Among other diagnostic issues, identifying the nature of mediastinal lymphadenopathy without recourse to a biopsy, in order to differentiate sarcoidosis and tuberculosis, remains challenging. Lee et al. [80] used quantitative imaging to discriminate sarcoidosis from tuberculosis lymphadenopathy, displaying significant differences in quantitative CT features between the two groups. All these studies make us consider the distant utopia of reaching a fully virtual biopsy, in which no tissue sample would be needed to obtain the same histological information, even if research and its clinical application are still at a preliminary stage.

Table 4. Radiomics and interstitial lung diseases.

\begin{tabular}{ccc}
\hline Study & Description & Cohort
\end{tabular}

154 radiomic features extracted

Schniering et al. (2019) - $\quad$ Aim: to evaluate the potential of CT [74] radiomics features for staging experimental ILD and assess transferability to human ILD
66 ILD CT (20 mild ILD Staging of ILD (proof of concept) and 46 advanced ILD) AUC 0.929
Extraction of 10 HRCT parameters

Aim: to assess the diagnostic performance of radiomic features in IPF

\section{Severity of IPF}

NL (normally attenuated lung) at $-200 \mathrm{HU}$ demonstrated the strongest correlation with disease severity $(p=0.009)$

Severity and staging of SSc-ILD

1116 extracted radiomic features $\quad 66$ SSc CT Aim: to retrospectively evaluate if radiomics features are able to detect ILD and distinguish the stages in SSc
Training cohort

$70 \%$

Validation cohort $30 \%$
- $\quad$ Radiomics features can predict GAP stage with a sensitivity of $84 \%$ and a specificity of almost $100 \%$. AUC 0.96 .

- Correlation of radiomics with GAP stage (but not with the visually defined features of ILD-HRCT)

\begin{tabular}{|c|c|c|c|c|}
\hline & & & & Correlation with PFTs in IIM associated ILD \\
\hline $\begin{array}{l}\text { Ungprasert et al. (2017) } \\
\text { [77] }\end{array}$ & - & $\begin{array}{l}\text { Extraction of quantitative CT indexes } \\
\text { with CALIPER } \\
\text { Aim: To evaluate the correlation } \\
\text { between } \\
\text { Quantitative HRCT analysis with } \\
\text { CALIPER software and pulmonary } \\
\text { function tests (PFTs) in patients with } \\
\text { idiopathic inflammatory myopathies } \\
\text { (IIM)-associated interstitial lung } \\
\text { disease (ILD). }\end{array}$ & $\begin{array}{l}110 \text { ILD CT } \\
-\quad 110 \text { baseline CT } \\
-\quad 110 \text { 1-year } \\
\text { follow-up CT }\end{array}$ & 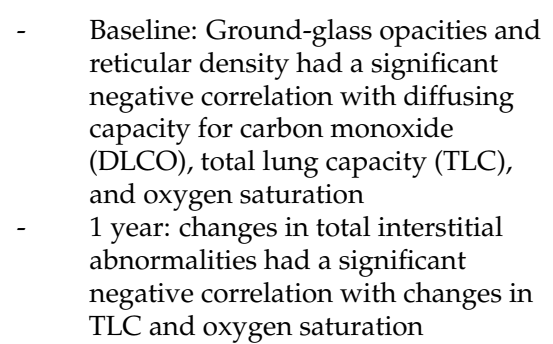 \\
\hline
\end{tabular}


Table 4. Cont.

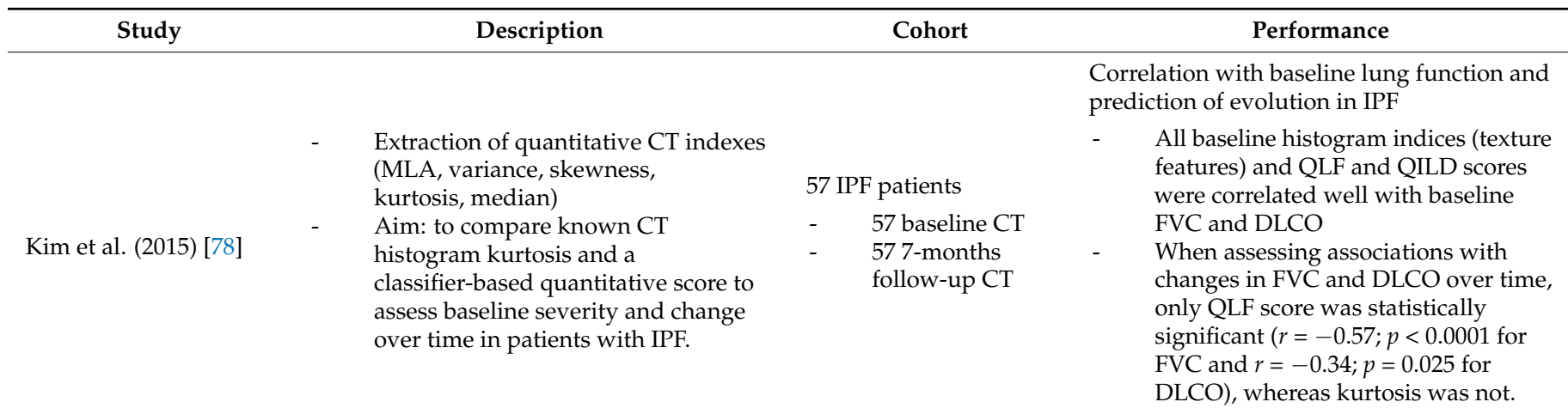

Differentiation NSIP vs. IPF

Extraction of quantitative $\mathrm{CT}$ indexes with CALIPER

De Giacomi et al. (2017) - $\quad$ Aim: to use quantitative CT analysis [79] to differentiate NSIP versus IPF and assess long-term survival

40 biopsy-confirmed UIP

20 biopsy-confirmed NSIP

- $\quad$ Compared with NSIP, IPF patients experienced greater functional decline $(\mathrm{CVF}, p=0.02)$ and radiologic progression (reticulation volume, $p=0.048)$.

- $\quad$ Both baseline and short-term changes in quantitative radiologic findings were predictive of mortality.

Differentiation between tuberculosis and sarcoidosis LN

Aim: to assess quantitative imaging in the evaluation of lymph nodes in pulmonary sarcoidosis and tuberculosis
$26 \mathrm{CT}$ from tubrcolosis patients, $21 \mathrm{CT}$ from sarcoidosis patients.

- $\quad$ Significant differences in the values of the Feret's diameter, perimeter, area, circularity, mean grey value, $\mathrm{SD}$, median, skewness, and kurtosis between tuberculous and sarcoid LNs $(p<0.05)$

Prediction of mortality and progression in IPF

Extraction of quantitative $\mathrm{CT}$ indexes (MLA, skewness, kurtosis) and visual scores (fibrosis, GGO, emphysema)

Best et al. (2008) [81]

Aim: to retrospectively evaluate quantitative $\mathrm{CT}$ indexes as predictors of mortality and describe 12-months changes in $\mathrm{CT}$ in IPF patients

\section{IPF patients \\ - $\quad 167$ baseline CT \\ - 1671 -year \\ follow-up CT}

- $\quad \operatorname{FVC}(p=0.006)$ and fibrosis $(p=0.002)$ were predictors of short-term mortality

Fibrosis index $(p=0.03)$, Mean Lung attenuation $(p=0.003)$, skewness $(p<0.001)$ and kurtosis $(p<0.001)$ predicted disease progression

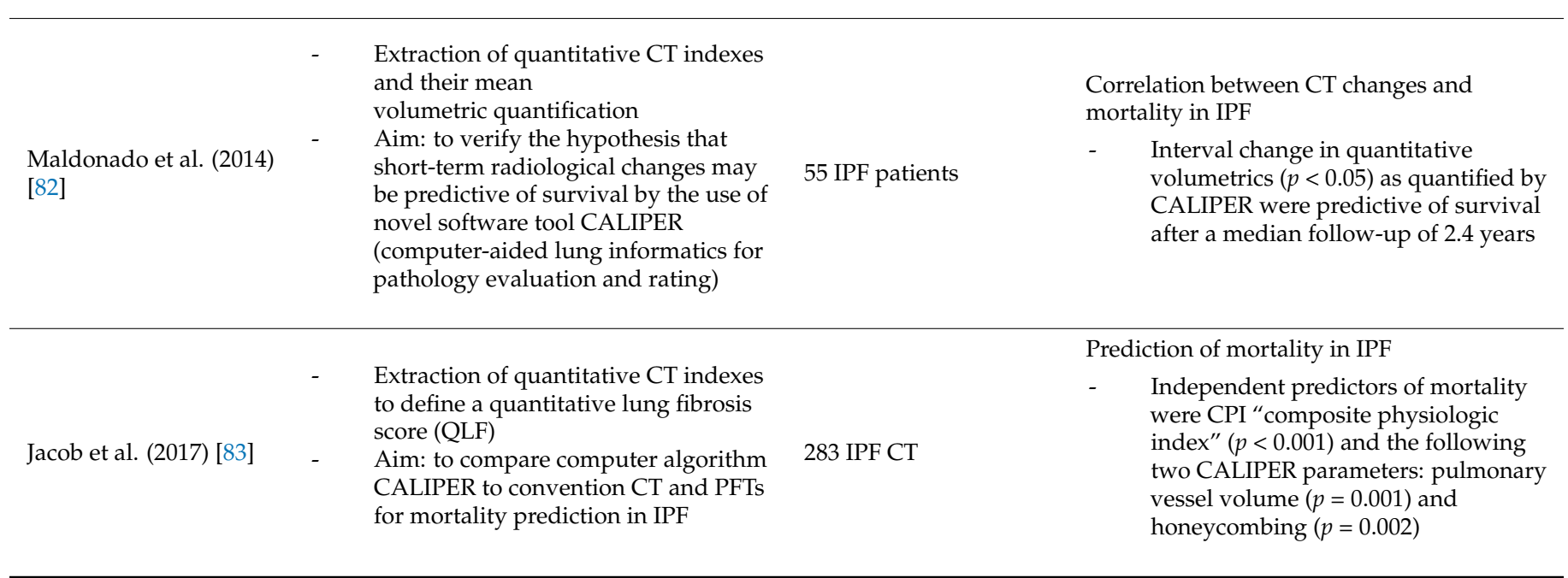


Table 4. Cont.

\begin{tabular}{|c|c|c|c|}
\hline Study & Description & Cohort & Performance \\
\hline & & & $\begin{array}{l}\text { Evaluate the effectiveness of } \\
\text { cyclophosphamide in SSc-ILD }\end{array}$ \\
\hline Kim et al. (2011) [84] & $\begin{array}{l}\text { - } \quad \text { Extraction of quantitative CT indexes } \\
\text { Aim: to assess the efficacy of } \\
\text { cyclophosphamide in SSc-ILD using } \\
\text { texture-based scores (impact on QLF) }\end{array}$ & $\begin{array}{l}83 \text { SSc-ILD CT } \\
-\quad 83 \text { baseline CT } \\
-\quad 831 \text {-year } \\
\quad \text { follow-up CT }\end{array}$ & $\begin{array}{ll}\text { - } & \text { Between-treatment } \\
\text { - } & \text { Difference in whole-lung QLF was } \\
\sim 5 \%(p=0.0190) . \\
\text { - }\end{array}$ \\
\hline
\end{tabular}

CT: Computed tomography, ILD: Interstitial Lunge disease, HRCT: High resolution computed tomography, AUC: Area under the curve, IPF: Idiopathic Pulmonary Fibrosis, SSc: Systemic sclerosis, CALIPER: Computer-aided lung informatics for pathology evaluation and rating, PFTs: Pulmonary function tests, MLA: Mean lung attenuation, QILD: Quantitative Interstitial Lunge disease, NSIP: Nonspecific interstitial pneumonia, QLF: Quantitative Lung Fibrosis, FVC: Forced vital capacity, CVF: Cobra Venom Factor, SD:standard deviatiosn, LNs: Lymph nodes, GGO: Groudn Glass Opacity and CPI: composite physiologic index.

Prognosis. The comparison of changes in radiological features led many teams to prove that radiomic features could predict the evolution of lung function, disease progression or mortality in ILD. In their study, by evaluating quantitative CT indexes and lung function, Best et al. [81] showed that forced vital capacity (FVC) and fibrosis index were predictors of short-term mortality in IPF, whereas more precise features (fibrosis index, mean lung attenuation, skewness and kurtosis) predicted disease progression. This is in line with the findings of Kim et al. [78], who demonstrated that quantitative lung fibrosis (QLF) score correlated well with changes in PFTs and disease progression in IPF. In the same perspective, other teams [82,83] used the CALIPER tool (computer-aided lung informatics for pathology evaluation and rating) to predict survival in IPF.

Therapy. Concerning the monitoring of response to therapy in ILD, few studies are currently available. Proving the usefulness of radiomics in this precise field, Kim et al. [84] assessed the efficacy of cyclophosphamide in scleroderma-related ILD, by using texturebased scores determining the QLF score. They established a significant change in QLF score after treatment, supporting the efficacy of cyclophosphamide over placebo, and also demonstrated a significant association between changes in QLF score, forced vital capacity (FVC) and dyspnea score. These few results, already promising, are the first signs of what radiomics could bring in the precise and quantifiable evaluation of the response to treatment in ILD.

\subsection{Vascular Lung Diseases}

The application of artificial intelligence in the field of vascular lung diseases is still at the preliminary stages. Only a few studies report results and mainly focus on pulmonary hypertension (PH). For example, Kiely et al. [85] managed to apply artificial intelligence in order to achieve a predictive model, using existing and real-world data to determine patients at high risk of idiopathic pulmonary hypertension, resulting in $99.99 \%$ specificity and $14.10 \%$ sensitivity.

However, it is strongly believed that AI and machine learning could be of high interest in the diagnostic and prognostic classification of $\mathrm{PH}$. For instance, one area of research is the accurate segmentation of cardiac chambers on MRI or CT, and the segmentation of the pulmonary vascular network [86,87]. One notable current limitation of imaging is the inability to properly assess distal pulmonary arterial vasculature, which is the pathological site interesting pulmonary arterial hypertension (PAH). Therefore, applying radiomics on CT or MRI imaging could lead to a more accurate evaluation of pulmonary perfusion [88]. Lastly, as PH diagnosis still relies on right heart catheterization (RHC), any non-invasive diagnostic tool could be highly welcomed. Lungu et al. [89] hypothesized that combining mathematical and cardiopulmonary metrics with AI classifiers could add diagnostic value. Their classifier showed that $92 \%$ of patients were correctly classified, which led to the 
conclusion that combining the $\mathrm{PH}$ biomarker with AI classification algorithms enhanced the diagnostic performance of non-invasive techniques in $\mathrm{PH}$.

\subsection{Pleural Diseases}

The rare studies exploring the pleura from a radiomic perspective only concern pleural tumor invasion in lung cancer. For example, Yang et al. [90] exposed a strong association between tumor imaging phenotype, as defined by radiomic features, and dry pleural dissemination. Studies are still needed in the field of radiomics, applied to benign or malignant primitive pleural diseases.

\section{Challenges and Limitations}

Being a novel and developing tool in medicine, radiomics is still inevitably facing challenges, limiting its wide use in clinical practice. These pitfalls can be found in most of the following steps of the radiomic workflow: from image acquisition to image segmentation, feature extraction, statistical analysis, and implementation in algorithms and real-life experience [51,91].

- Image acquisition: There is a disparity in acquisition parameters, as there are no real standardized imaging protocols. For example, there are differences in dose administration, reconstruction kernels, section thickness between the different imaging centers, and modalities. Moreover, variations in inspiratory effort can modify lung attenuation and volume, possibly leading to misinterpretation, affecting both threshold- and histogram-based quantification.

- Image segmentation: There is an inevitable intra- and inter-observer variability in manual segmentation methods, which could be improved by the use of semi- or fully automatic techniques. Similarly, intra-lesional heterogeneity can be a real challenge for accurate segmentation, as well as motion artifacts or noisy background due to low-dose scanning.

- Feature extraction: There is a risk of confusion between the signal of the ROI and the background noise, which could be improved by the development of filtering techniques, or by resampling strategies. Moreover, feature selection is facing disparities imputable to human error, which could be improved by the implementation of deep learning methods such as $\mathrm{CNN}$.

- Statistical analysis: There is a disproportion between the tremendous number of possible features and the small population, generating a high rate of false positives (elegantly called "curse of dimensionality" [51]), which could be improved by the development of statistical corrections or cross-validation.

- Implementation and reproducibility: There is a lack of reproducibility between research groups, which could be improved by increasing the access to full data, extraction software and statistical methods. Another example of a limitation is misinterpretation from a trained algorithm. Indeed, a specific algorithm can only define a disease for which it was trained, possibly leading to the false suggestion of diseases sharing some common features.

- $\quad$ Robustness and Explainability of Artificial Intelligence: There are numerous issues to be addressed, concerning the application of AI in real life. For example, the use of extensive data in the development of machine learning models does not imply the automatic understanding of underlying mechanisms linking data. Moreover, AI systems can face concerns regarding reliability, as they may accumulate edge cases that are not taken into account by the algorithm. Lastly, the question of data protection must be raised, as potential matters concerning confidentiality can surface [92].

Recognition of the current limitations of radiomics is essential to avoid misleading to inappropriate or non-reproducible models. For example, in this perspective, Ibrahim et al. [93] proposed a workflow for accurate radiomic analysis. Standardization of imaging acquisition, segmentation, feature extraction, and calculation is fundamental to ensure robustness and dissemination of radiomics as a paraclinical tool in medicine. 


\section{Conclusions and Perspective}

At the era of precision medicine, where personalized work-up and treatment according to individual variability is unavoidable, imaging biomarkers integrating information from extensive data is seen as a revolution. Radiomics is cementing its position as a promising tool in lung diseases, integrating data from imaging, clinical, histological and genomic information. Significant effort is being put into the investigation and resolution of its inherent limitations. The research is extensive and aims to progressively lead to its clinical application and routine utilization in real-life practice.

Author Contributions: Conceptualization, A.-N.F. and J.G.; methodology, A.-N.F.; investigation, A.-N.F.; writing—original draft preparation, A.-N.F. writing—review and editing, C.D., F.C., F.B., T.R., P.L. (Philippe Lambin), A.V. and R.T.H.L.; supervision, R.H., R.L., P.L. (Philippe Lambin), W.V., S.W., M.O., P.L. (Pierre Lovinfosse) and P.M. All authors have read and agreed to the published version of the manuscript.

Funding: This research received no external funding.

Conflicts of Interest: The authors declare the following financial interests/personal relationships, which may be considered as potential competing interests: Fabio Bottari, Akshayaa Vaidyanathan and Mariaelena Occhipinti are salaried employees of Radiomics. Philippe Lambin reports, within and outside the submitted work, grants/sponsored research agreements from Varian medical, Radiomics, ptTheragnostic/DNAmito, Health Innovation Ventures. He received an advisor/presenter fee and/or reimbursement of travel costs/external grant writing fee and/or in kind manpower contribution from Radiomics, BHV, Merck, Varian, Elekta, ptTheragnostic and Convert Pharmaceuticals. Lambin has shares in the companies Radiomics, Convert Pharmaceuticals SA and The Medical Cloud Company SPRL, and is the co-inventor of two issued patents with royalties on radiomics (PCT/NL2014/050248, PCT/NL2014/050728), licensed to Radiomics, and one issue patent on mtDNA (PCT/EP2014/059089), licensed to ptTheragnostic/DNAmito, three non-patented invention (software), licensed to ptTheragnostic/DNAmito, Radiomics and Health Innovation Ventures, and three non-issues, non-licensed patents on Deep Learning-Radiomics and LSRT (N2024482, N2024889, N2024889). Ralph T.H. Leijenaar has shares in the company Radiomics and is co-inventor of an issued patent with royalties on radiomics (PCT/NL2014/050728), licensed to Radiomics. Sean Walsh and Wim Vos have shares in the company Radiomics. The rest of the co-authors have no known competing financial interests or personal relationships to declare.

$\begin{array}{ll}\text { Abbreviations } \\ \text { AI } & \text { Artificial Intelligence } \\ \text { CT } & \text { Computed Tomography } \\ \text { MRI } & \text { Magnetic Resonance Imaging } \\ \text { PET } & \text { Positron Emission Tomography } \\ \text { DL } & \text { Deep Learning } \\ \text { IPF } & \text { Idiopathic Pulmonary Fibrosis } \\ \text { CPFE } & \text { Combined Pulmonary Fibrosis and Emphysema } \\ \text { QIN } & \text { Quantitative Imaging Network } \\ \text { VTD } & \text { Volume Doubling Time } \\ \text { SSPNs } & \text { Small Solitary Pulmonary Nodules } \\ \text { AUC } & \text { Area Under the Curve } \\ \text { HRCT } & \text { High-Resolution Computed Tomography } \\ \text { CNN } & \text { Convolutional Neural Networks } \\ \text { CAD } & \text { Computer-Aided Detection/Diagnosis } \\ \text { NLST } & \text { National Lung Screening Trial } \\ \text { EGFR } & \text { Epidermal Growth Factor Receptor } \\ \text { NSCLC } & \text { Non-Small Cell Lung Carcinoma } \\ \text { GTV } & \text { Gross-Tumor Volume } \\ \text { TKI } & \text { Tyrosine Kinase Inhibitors } \\ \text { COPD } & \text { Chronic Obstructive Pulmonary Disease } \\ \text { HU } & \text { Hounsfield Unit }\end{array}$




$\begin{array}{ll}\text { PRM } & \text { Parametric Response Mapping } \\ \text { PFTs } & \text { Pulmonary Function Tests } \\ \text { LVR } & \text { Lung Volume Reduction } \\ \text { ICS } & \text { Inhaled Corticosteroids } \\ \text { ILD } & \text { Interstitial Lung Diseases } \\ \text { NSIP } & \text { Non-Specific Interstitial Pneumonia } \\ \text { CALIPER } & \text { Computer-Aided Lung Informatics for Pathology Evaluation and Rating } \\ \text { FVC } & \text { Forced Vital Capacity } \\ \text { QLF } & \text { Quantitative Lung Fibrosis } \\ \text { PH } & \text { Pulmonary Hypertension } \\ \text { PAH } & \text { Pulmonary Arterial Hypertension } \\ \text { RHC } & \text { Right Heart Catheterization } \\ \text { ROI } & \text { Region of Interest }\end{array}$

\section{References}

1. Lambin, P.; Rios-Velazquez, E.; Leijenaar, R.; Carvalho, S.; van Stiphout, R.G.P.M.; Granton, P.; Zegers, C.M.L.; Gillies, R.; Boellard, R.; Dekker, A.; et al. Radiomics: Extracting more information from medical images using advanced feature analysis. Eur. J. Cancer 2012, 48, 441-446. [CrossRef] [PubMed]

2. Wilson, D.O.; Ryan, A.; Fuhrman, C.; Schuchert, M.; Shapiro, S.; Siegfried, J.M.; Weissfeld, J. Doubling Times and CT ScreenDetected Lung Cancers in the Pittsburgh Lung Screening Study. Am. J. Respir. Crit. Care Med. 2012, 185, 85-89. [CrossRef]

3. Hasegawa, M.; Sone, S.; Takashima, S.; Li, F.; Yang, Z.G.; Maruyama, Y.; Watanabe, T. Growth rate of small lung cancers detected on mass CT screening. Br. J. Radiol. 2000, 73, 1252-1259. [CrossRef] [PubMed]

4. Ko, J.P.; Berman, E.J.; Kaur, M.; Babb, J.S.; Bomsztyk, E.; Greenberg, A.K.; Naidich, D.P.; Rusinek, H. Pulmonary Nodules: Growth Rate Assessment in Patients by Using Serial CT and Three-dimensional Volumetry. Radiology 2012, 262, 662-671. [CrossRef] [PubMed]

5. Nordstrom, R.J. The Quantitative Imaging Network in Precision Medicine. Tomography 2016, 2, 239-241. [CrossRef] [PubMed]

6. Ather, S.; Kadir, T.; Gleeson, F. Artificial intelligence and radiomics in pulmonary nodule management: Current status and future applications. Clin. Radiol. 2020, 75, 13-19. [CrossRef]

7. Chen, C.-H.; Chang, C.-K.; Tu, C.-Y.; Liao, W.-C.; Wu, B.-R.; Chou, K.-T.; Chiou, Y.-R.; Yang, S.-N.; Zhang, G.; Huang, T.-C. Radiomic features analysis in computed tomography images of lung nodule classification. PLoS ONE 2018, 13, e0192002. [CrossRef] [PubMed]

8. Horeweg, N.; van der Aalst, C.M.; Vliegenthart, R.; Zhao, Y.; Xie, X.; Scholten, E.T.; Mali, W.; Thunnissen, E.; Weenink, C.; Groen, H.J.M.; et al. Volumetric computed tomography screening for lung cancer: Three rounds of the NELSON trial. Eur. Respir. J. 2013, 42, 1659-1667. [CrossRef]

9. de Koning, H.J.; van der Aalst, C.M.; de Jong, P.A.; Scholten, E.T.; Nackaerts, K.; Heuvelmans, M.A.; Lammers, J.-W.J.; Weenink, C.; Yousaf-Khan, U.; Horeweg, N.; et al. Reduced Lung-Cancer Mortality with Volume CT Screening in a Randomized Trial. N. Engl. J. Med. 2020, 382, 503-513. [CrossRef]

10. Ma, J.; Wang, Q.; Ren, Y.; Hu, H.; Zhao, J. Automatic lung nodule classification with radiomics approach. In Medical Imaging 2016: PACS and Imaging Informatics: Next Generation and Innovations; Zhang, J., Cook, T.S., Eds.; International Society for Optics and Photonics: San Diego, CA, USA, 2016; p. 978906. Available online: http:/ / proceedings.spiedigitallibrary.org/proceeding.aspx? doi=10.1117/12.2220768 (accessed on 21 June 2021).

11. Hawkins, S.; Wang, H.; Liu, Y.; Garcia, A.; Stringfield, O.; Krewer, H.; Li, Q.; Cherezov, D.; Gatenby, R.A.; Balagurunathan, Y.; et al. Predicting Malignant Nodules from Screening CT Scans. J. Thorac. Oncol. 2016, 11, 2120-2128. [CrossRef]

12. Huang, P.; Park, S.; Yan, R.; Lee, J.; Chu, L.C.; Lin, C.T.; Hussien, A.; Rathmell, J.; Thomas, B.; Chen, C.; et al. Added Value of Computer-aided CT Image Features for Early Lung Cancer Diagnosis with Small Pulmonary Nodules: A Matched Case-Control Study. Radiology 2018, 286, 286-295. [CrossRef] [PubMed]

13. Uthoff, J.; Stephens, M.J.; Newell, J.D.; Hoffman, E.A.; Larson, J.; Koehn, N.; De Stefano, F.A.; Lusk, C.M.; Wenzlaff, A.S.; Watza, D.; et al. Machine learning approach for distinguishing malignant and benign lung nodules utilizing standardized perinodular parenchymal features from CT. Med. Phys. 2019, 46, 3207-3216. [CrossRef] [PubMed]

14. Mao, L.; Chen, H.; Liang, M.; Li, K.; Gao, J.; Qin, P.; Ding, X.; Li, X.; Liu, X. Quantitative radiomic model for predicting malignancy of small solid pulmonary nodules detected by low-dose CT screening. Quant. Imaging Med. Surg. 2019, 9, 263-272. [CrossRef] [PubMed]

15. ACR. Lung CT Screening Reporting \& Data System (Lung-RADS). Available online: https:/ / www.acr.org (accessed on 20 April 2021).

16. Lee, S.H.; Lee, S.M.; Goo, J.M.; Kim, K.-G.; Kim, Y.J.; Park, C.M. Usefulness of Texture Analysis in Differentiating Transient from Persistent Part-solid Nodules(PSNs): A Retrospective Study. PLoS ONE 2014, 9, e85167.

17. Autrusseau, P.-A.; Labani, A.; De Marini, P.; Leyendecker, P.; Hintzpeter, C.; Ortlieb, A.-C.; Calhoun, M.; Goldberg, I.; Roy, C.; Ohana, M. Radiomics in the evaluation of lung nodules: Intrapatient concordance between full-dose and ultra-low-dose chest computed tomography. Diagn. Interv. Imaging 2021, 102, 233-239. [CrossRef] 
18. Maldonado, F.; Varghese, C.; Rajagopalan, S.; Duan, F.; Balar, A.B.; Lakhani, D.A.; Antic, S.L.; Massion, P.P.; Johnson, T.F.; Karwoski, R.A.; et al. Validation of the BRODERS classifier (Benign versus aggRessive nODule Evaluation using Radiomic Stratification), a novel HRCT-based radiomic classifier for indeterminate pulmonary nodules. Eur. Respir. J. 2021, $57,2002485$. [CrossRef]

19. Murphy, A.; Skalski, M.; Gaillard, F. The utilisation of convolutional neural networks in detecting pulmonary nodules: A review. Br. J. Radiol. 2018, 91, 20180028. [CrossRef]

20. da Silva, G.L.F.; Valente, T.L.A.; Silva, A.C.; de Paiva, A.C.; Gattass, M. Convolutional neural network-based PSO for lung nodule false positive reduction on CT images. Comput. Methods Programs Biomed. 2018, 162, 109-118. [CrossRef]

21. Li, S.; Xu, P.; Li, B.; Chen, L.; Zhou, Z.; Hao, H.; Duan, Y.; Folkert, M.; Ma, J.; Huang, S.; et al. Predicting lung nodule malignancies by combining deep convolutional neural network and handcrafted features. Phys. Med. Biol. 2019, 64, 175012. [CrossRef]

22. Mehta, K.; Jain, A.; Mangalagiri, J.; Menon, S.; Nguyen, P.; Chapman, D.R. Lung Nodule Classification Using Biomarkers, Volumetric Radiomics, and 3D CNNs. J. Digit. Imaging 2021. [CrossRef]

23. Wu, W.; Parmar, C.; Grossmann, P.; Quackenbush, J.; Lambin, P.; Bussink, J.; Mak, R.; Aerts, H.J.W.L. Exploratory Study to Identify Radiomics Classifiers for Lung Cancer Histology. Front. Oncol. 2016, 6, 71. [CrossRef]

24. Digumarthy, S.R.; Padole, A.M.; Rastogi, S.; Price, M.; Mooradian, M.J.; Sequist, L.V.; Kalra, M.K. Predicting malignant potential of subsolid nodules: Can radiomics preempt longitudinal follow up CT? Cancer Imaging 2019, 19, 36. [CrossRef]

25. Radiomics of Lung Nodules: A Multi-Institutional Study of Robustness and Agreement of Quantitative Imaging Features. Tomography 2016, 2, 430-437. [CrossRef] [PubMed]

26. Balagurunathan, Y.; Gu, Y.; Wang, H.; Kumar, V.; Grove, O.; Hawkins, S.; Kim, J.; Goldgof, D.B.; Hall, L.O.; Gatenby, R.A.; et al. Reproducibility and Prognosis of Quantitative Features Extracted from CT Images. Transl. Oncol. 2014, 7, 72-87. [CrossRef] [PubMed]

27. Sung, H.; Ferlay, J.; Siegel, R.L.; Laversanne, M.; Soerjomataram, I.; Jemal, A.; Bray, F. Global Cancer Statistics 2020: GLOBOCAN Estimates of Incidence and Mortality Worldwide for 36 Cancers in 185 Countries. CA Cancer J. Clin. 2021, 71, 209-249. [CrossRef]

28. The National Lung Screening Trial Research Team Reduced Lung-Cancer Mortality with Low-Dose Computed Tomographic Screening. N. Engl. J. Med. 2011, 365, 395-409. [CrossRef] [PubMed]

29. National Lung Screening Trial Research Team Lung Cancer Incidence and Mortality with Extended Follow-up in the National Lung Screening Trial. J. Thorac. Oncol. Off. Publ. Int. Assoc. Study Lung Cancer 2019, 14, 1732-1742.

30. Refaee, T.; Wu, G.; Ibrahim, A.; Halilaj, I.; Leijenaar, R.T.H.; Rogers, W.; Gietema, H.A.; Hendriks, L.E.L.; Lambin, P.; Woodruff, H.C. The Emerging Role of Radiomics in COPD and Lung Cancer. Respiration 2020, 99, 99-107. [CrossRef] [PubMed]

31. Aerts, H.J.W.L.; Velazquez, E.R.; Leijenaar, R.T.H.; Parmar, C.; Grossmann, P.; Carvalho, S.; Cavalho, S.; Bussink, J.; Monshouwer, R.; Haibe-Kains, B.; et al. Decoding tumour phenotype by noninvasive imaging using a quantitative radiomics approach. Nat. Commun. 2014, 5, 4006. [CrossRef]

32. Maldonado, F.; Boland, J.M.; Raghunath, S.; Aubry, M.C.; Bartholmai, B.J.; Deandrade, M.; Hartman, T.E.; Karwoski, R.A.; Rajagopalan, S.; Sykes, A.-M.; et al. Noninvasive characterization of the histopathologic features of pulmonary nodules of the lung adenocarcinoma spectrum using computer-aided nodule assessment and risk yield (CANARY)—A pilot study. J. Thorac. Oncol. Off. Publ. Int. Assoc. Study Lung Cancer 2013, 8, 452-460. [CrossRef]

33. Liu, Y.; Balagurunathan, Y.; Atwater, T.; Antic, S.; Li, Q.; Walker, R.C.; Smith, G.T.; Massion, P.P.; Schabath, M.B.; Gillies, R.J. Radiological Image Traits Predictive of Cancer Status in Pulmonary Nodules. Clin. Cancer Res. Off. J. Am. Assoc. Cancer Res. 2017, 23, 1442-1449. [CrossRef] [PubMed]

34. Yu, L.; Tao, G.; Zhu, L.; Wang, G.; Li, Z.; Ye, J.; Chen, Q. Prediction of pathologic stage in non-small cell lung cancer using machine learning algorithm based on CT image feature analysis. BMC Cancer 2019, 19, 464. [CrossRef] [PubMed]

35. Zhang, L.; Chen, B.; Liu, X.; Song, J.; Fang, M.; Hu, C.; Dong, D.; Li, W.; Tian, J. Quantitative Biomarkers for Prediction of Epidermal Growth Factor Receptor Mutation in Non-Small Cell Lung Cancer. Transl. Oncol. 2018, 11, 94-101. [CrossRef]

36. Liu, Y.; Kim, J.; Balagurunathan, Y.; Li, Q.; Garcia, A.L.; Stringfield, O.; Ye, Z.; Gillies, R.J. Radiomic Features Are Associated With EGFR Mutation Status in Lung Adenocarcinomas. Clin. Lung Cancer 2016, 17, 441-448.e6. [CrossRef]

37. Rios Velazquez, E.; Parmar, C.; Liu, Y.; Coroller, T.P.; Cruz, G.; Stringfield, O.; Ye, Z.; Makrigiorgos, M.; Fennessy, F.; Mak, R.H.; et al. Somatic Mutations Drive Distinct Imaging Phenotypes in Lung Cancer. Cancer Res. 2017, 77, 3922-3930. [CrossRef]

38. Weiss, G.J.; Ganeshan, B.; Miles, K.A.; Campbell, D.H.; Cheung, P.Y.; Frank, S.; Korn, R.L. Noninvasive Image Texture Analysis Differentiates K-ras Mutation from Pan-Wildtype NSCLC and Is Prognostic. PLoS ONE 2014, 9, e100244.

39. Tang, C.; Hobbs, B.; Amer, A.; Li, X.; Behrens, C.; Canales, J.R.; Cuentas, E.P.; Villalobos, P.; Fried, D.; Chang, J.Y.; et al. Development of an Immune-Pathology Informed Radiomics Model for Non-Small Cell Lung Cancer. Sci. Rep. $2018,8,1922$. [CrossRef] [PubMed]

40. Wu, G.; Woodruff, H.C.; Shen, J.; Refaee, T.; Sanduleanu, S.; Ibrahim, A.; Leijenaar, R.T.H.; Wang, R.; Xiong, J.; Bian, J.; et al. Diagnosis of Invasive Lung Adenocarcinoma Based on Chest CT Radiomic Features of Part-Solid Pulmonary Nodules: A Multicenter Study. Radiology 2020, 297, E282. [CrossRef]

41. Coroller, T.P.; Grossmann, P.; Hou, Y.; Rios Velazquez, E.; Leijenaar, R.T.H.; Hermann, G.; Lambin, P.; Haibe-Kains, B.; Mak, R.H.; Aerts, H.J.W.L. CT-based radiomic signature predicts distant metastasis in lung adenocarcinoma. Radiother. Oncol. 2015, 114, 345-350. [CrossRef] 
42. Song, J.; Liu, Z.; Zhong, W.; Huang, Y.; Ma, Z.; Dong, D.; Liang, C.; Tian, J. Non-small cell lung cancer: Quantitative phenotypic analysis of CT images as a potential marker of prognosis. Sci. Rep. 2016, 6, 38282. [CrossRef]

43. He, L.; Huang, Y.; Yan, L.; Zheng, J.; Liang, C.; Liu, Z. China Radiomics-based predictive risk score: A scoring system for preoperatively predicting risk of lymph node metastasis in patients with resectable non-small cell lung cancer. Chin. J. Cancer Res. 2019, 31, 641-652. [CrossRef] [PubMed]

44. Hosny, A.; Parmar, C.; Coroller, T.P.; Grossmann, P.; Zeleznik, R.; Kumar, A.; Bussink, J.; Gillies, R.J.; Mak, R.H.; Aerts, H.J.W.L. Deep learning for lung cancer prognostication: A retrospective multi-cohort radiomics study. PLOS Med. 2018, 15, e1002711. [CrossRef] [PubMed]

45. Ferreira Junior, J.R.; Koenigkam-Santos, M.; Cipriano, F.E.G.; Fabro, A.T.; Azevedo-Marques, P.M. de Radiomics-based features for pattern recognition of lung cancer histopathology and metastases. Comput. Methods Programs Biomed. 2018, 159, 23-30. [CrossRef] [PubMed]

46. Mattonen, S.A.; Palma, D.A.; Johnson, C.; Louie, A.V.; Landis, M.; Rodrigues, G.; Chan, I.; Etemad-Rezai, R.; Yeung, T.P.C.; Senan, S.; et al. Detection of Local Cancer Recurrence After Stereotactic Ablative Radiation Therapy for Lung Cancer: Physician Performance Versus Radiomic Assessment. Int. J. Radiat. Oncol. 2016, 94, 1121-1128. [CrossRef] [PubMed]

47. Chetan, M.R.; Gleeson, F.V. Radiomics in predicting treatment response in non-small-cell lung cancer: Current status, challenges and future perspectives. Eur. Radiol. 2021, 31, 1049-1058. [CrossRef]

48. Bera, K.; Velcheti, V.; Madabhushi, A. Novel Quantitative Imaging for Predicting Response to Therapy: Techniques and Clinical Applications. Am. Soc. Clin. Oncol. Educ. Book 2018, 38, 1008-1018. [CrossRef]

49. Coroller, T.P.; Agrawal, V.; Narayan, V.; Hou, Y.; Grossmann, P.; Lee, S.W.; Mak, R.H.; Aerts, H.J.W.L. Radiomic phenotype features predict pathological response in non-small cell lung cancer. Radiother. Oncol. 2016, 119, 480-486. [CrossRef]

50. Kim, H.; Park, C.M.; Keam, B.; Park, S.J.; Kim, M.; Kim, T.M.; Kim, D.-W.; Heo, D.S.; Goo, J.M. The prognostic value of CT radiomic features for patients with pulmonary adenocarcinoma treated with EGFR tyrosine kinase inhibitors. PLoS ONE 2017, 12, e0187500. [CrossRef]

51. Limkin, E.J.; Sun, R.; Dercle, L.; Zacharaki, E.I.; Robert, C.; Reuzé, S.; Schernberg, A.; Paragios, N.; Deutsch, E.; Ferté, C. Promises and challenges for the implementation of computational medical imaging (radiomics) in oncology. Ann. Oncol. 2017, 28, 1191-1206. [CrossRef]

52. Lafata, K.J.; Zhou, Z.; Liu, J.-G.; Hong, J.; Kelsey, C.R.; Yin, F.-F. An Exploratory Radiomics Approach to Quantifying Pulmonary Function in CT Images. Sci. Rep. 2019, 9, 11509. [CrossRef]

53. Gevenois, P.A.; de Maertelaer, V.; De Vuyst, P.; Zanen, J.; Yernault, J.C. Comparison of computed density and macroscopic morphometry in pulmonary emphysema. Am. J. Respir. Crit. Care Med. 1995, 152, 653-657. [CrossRef] [PubMed]

54. Madani, A.; Zanen, J.; de Maertelaer, V.; Gevenois, P.A. Pulmonary emphysema: Objective quantification at multi-detector row CT-comparison with macroscopic and microscopic morphometry. Radiology 2006, 238, 1036-1043. [CrossRef]

55. de Jong, P.A.; Müller, N.L.; Paré, P.D.; Coxson, H.O. Computed tomographic imaging of the airways: Relationship to structure and function. Eur. Respir. J. 2005, 26, 140-152. [CrossRef] [PubMed]

56. Madani, A.; Van Muylem, A.; Gevenois, P.A. Pulmonary Emphysema: Effect of Lung Volume on Objective Quantification at Thin-Section CT. Radiology 2010, 257, 260-268. [CrossRef]

57. Bankier, A.A.; De Maertelaer, V.; Keyzer, C.; Gevenois, P.A. Pulmonary Emphysema: Subjective Visual Grading versus Objective Quantification with Macroscopic Morphometry and Thin-Section CT Densitometry. Radiology 1999, 211, 851-858. [CrossRef]

58. Mohamed Hoesein, F.A.A.; de Hoop, B.; Zanen, P.; Gietema, H.; Kruitwagen, C.L.J.J.; van Ginneken, B.; Isgum, I.; Mol, C.; van Klaveren, R.J.; Dijkstra, A.E.; et al. CT-quantified emphysema in male heavy smokers: Association with lung function decline. Thorax 2011, 66, 782-787. [CrossRef]

59. Pompe, E.; van Rikxoort, E.M.; Schmidt, M.; Rühaak, J.; Estrella, L.G.; Vliegenthart, R.; Oudkerk, M.; de Koning, H.J.; van Ginneken, B.; de Jong, P.A.; et al. Parametric response mapping adds value to current computed tomography biomarkers in diagnosing chronic obstructive pulmonary disease. Am. J. Respir. Crit. Care Med. 2015, 191, 1084-1086. [CrossRef]

60. Hackx, M.; Francotte, D.; Garcia, T.S.; Van Muylem, A.; Walsdorff, M.; Gevenois, P.A. Effect of total lung capacity, gender and height on CT airway measurements. Br. J. Radiol. 2017, 90, 20160898. [CrossRef]

61. Ginsburg, S.B.; Lynch, D.A.; Bowler, R.P.; Schroeder, J.D. Automated Texture-based Quantification of Centrilobular Nodularity and Centrilobular Emphysema in Chest CT Images. Acad. Radiol. 2012, 19, 1241-1251. [CrossRef]

62. Martini, K.; Frauenfelder, T. Advances in imaging for lung emphysema. Ann. Transl. Med. 2020, 8, 1467. [CrossRef]

63. Lynch, D.A.; Austin, J.H.M.; Hogg, J.C.; Grenier, P.A.; Kauczor, H.-U.; Bankier, A.A.; Barr, R.G.; Colby, T.V.; Galvin, J.R.; Gevenois, P.A.; et al. CT-Definable Subtypes of Chronic Obstructive Pulmonary Disease: A Statement of the Fleischner Society. Radiology 2015, 277, 192-205. [CrossRef]

64. Occhipinti, M.; Paoletti, M.; Bartholmai, B.J.; Rajagopalan, S.; Karwoski, R.A.; Nardi, C.; Inchingolo, R.; Larici, A.R.; Camiciottoli, G.; Lavorini, F.; et al. Spirometric assessment of emphysema presence and severity as measured by quantitative CT and CT-based radiomics in COPD. Respir. Res. 2019, 20, 101. [CrossRef]

65. Cho, Y.H.; Seo, J.B.; Lee, S.M.; Kim, N.; Yun, J.; Hwang, J.E.; Lee, J.S.; Oh, Y.-M.; Do Lee, S.; Loh, L.-C.; et al. Radiomics approach for survival prediction in chronic obstructive pulmonary disease. Eur. Radiol. 2021. [CrossRef] 
66. Cho, Y.H.; Lee, S.M.; Seo, J.B.; Kim, N.; Bae, J.P.; Lee, J.S.; Oh, Y.-M.; Do-Lee, S. Quantitative assessment of pulmonary vascular alterations in chronic obstructive lung disease: Associations with pulmonary function test and survival in the KOLD cohort. Eur. J. Radiol. 2018, 108, 276-282. [CrossRef]

67. Stockley, R.A.; Parr, D.G.; Piitulainen, E.; Stolk, J.; Stoel, B.C.; Dirksen, A. Therapeutic efficacy of alpha-1 antitrypsin augmentation therapy on the loss of lung tissue: An integrated analysis of 2 randomised clinical trials using computed tomography densitometry. Respir. Res. 2010, 11, 136. [CrossRef]

68. Chandra, D.; Lipson, D.A.; Hoffman, E.A.; Hansen-Flaschen, J.; Sciurba, F.C.; DeCamp, M.M.; Reilly, J.J.; Washko, G.R. Perfusion Scintigraphy and Patient Selection for Lung Volume Reduction Surgery. Am. J. Respir. Crit. Care Med. 2010, 182, 937-946. [CrossRef]

69. Milanese, G.; Silva, M.; Sverzellati, N. Lung volume reduction of pulmonary emphysema: The radiologist task. Curr. Opin. Pulm. Med. 2016, 22, 179-186. [CrossRef]

70. Gupta, S.; Hartley, R.; Khan, U.T.; Singapuri, A.; Hargadon, B.; Monteiro, W.; Pavord, I.D.; Sousa, A.R.; Marshall, R.P.; Subramanian, D.; et al. Quantitative computed tomography-derived clusters: Redefining airway remodeling in asthmatic patients. $J$. Allergy Clin. Immunol. 2014, 133, 729-738.e18. [CrossRef]

71. Choi, S.; Hoffman, E.A.; Wenzel, S.E.; Castro, M.; Fain, S.; Jarjour, N.; Schiebler, M.L.; Chen, K.; Lin, C.-L. Quantitative computed tomographic imaging-based clustering differentiates asthmatic subgroups with distinctive clinical phenotypes. J. Allergy Clin. Immunol. 2017, 140, 690-700.e8. [CrossRef]

72. Tunon-de-Lara, J.-M.; Laurent, F.; Giraud, V.; Perez, T.; Aguilaniu, B.; Meziane, H.; Basset-Merle, A.; Chanez, P. Air trapping in mild and moderate asthma: Effect of inhaled corticosteroids. J. Allergy Clin. Immunol. 2007, 119, 583-590. [CrossRef]

73. Walsh, S.L.F.; Calandriello, L.; Silva, M.; Sverzellati, N. Deep learning for classifying fibrotic lung disease on high-resolution computed tomography: A case-cohort study. Lancet Respir. Med. 2018, 6, 837-845. [CrossRef]

74. Schniering, J.; Gabrys, H.; Brunner, M.; Distler, O.; Guckenberger, M.; Bogowicz, M.; Vuong, D.; Karava, K.; Müller, C.; Frauenfelder, T.; et al. Computed-tomography-based radiomics features for staging of interstitial lung disease-Transferability from experimental to human lung fibrosis-A proof-of-concept study. Eur. Respir. Soc. 2019, 54, PA4806. Available online: http:/ / erj.ersjournals.com/lookup/doi/10.1183/13993003.congress-2019.PA4806 (accessed on 23 October 2020).

75. Stefano, A.; Gioè, M.; Russo, G.; Palmucci, S.; Torrisi, S.E.; Bignardi, S.; Basile, A.; Comelli, A.; Benfante, V.; Sambataro, G.; et al. Performance of Radiomics Features in the Quantification of Idiopathic Pulmonary Fibrosis from HRCT. Diagnostics 2020, 10, 306. [CrossRef] [PubMed]

76. Martini, K.; Baessler, B.; Bogowicz, M.; Blüthgen, C.; Mannil, M.; Tanadini-Lang, S.; Schniering, J.; Maurer, B.; Frauenfelder, T. Applicability of radiomics in interstitial lung disease associated with systemic sclerosis: Proof of concept. Eur. Radiol. 2021, 31, 1987-1998. [CrossRef]

77. Ungprasert, P.; Wilton, K.M.; Ernste, F.C.; Kalra, S.; Crowson, C.S.; Rajagopalan, S.; Bartholmai, B.J. Novel Assessment of Interstitial Lung Disease Using the "Computer-Aided Lung Informatics for Pathology Evaluation and Rating" (CALIPER) Software System in Idiopathic Inflammatory Myopathies. Lung 2017, 195, 545-552. [CrossRef] [PubMed]

78. Kim, H.J.; Brown, M.S.; Chong, D.; Gjertson, D.W.; Lu, P.; Kim, H.J.; Coy, H.; Goldin, J.G. Comparison of the Quantitative CT Imaging Biomarkers of Idiopathic Pulmonary Fibrosis at Baseline and Early Change with an Interval of 7 Months. Acad. Radiol. 2015, 22, 70-80. [CrossRef]

79. De Giacomi, F.; Raghunath, S.; Karwoski, R.; Bartholmai, B.J.; Moua, T. Short-term Automated Quantification of Radiologic Changes in the Characterization of Idiopathic Pulmonary Fibrosis Versus Nonspecific Interstitial Pneumonia and Prediction of Long-term Survival. J. Thorac. Imaging 2018, 33, 124-131. [CrossRef] [PubMed]

80. Lee, C.U.; Chong, S.; Choi, H.W.; Choi, J.C. Quantitative image analysis using chest computed tomography in the evaluation of lymph node involvement in pulmonary sarcoidosis and tuberculosis. PLoS ONE 2018, 13, e0207959. [CrossRef] [PubMed]

81. Best, A.C.; Meng, J.; Lynch, A.M.; Bozic, C.M.; Miller, D.; Grunwald, G.K.; Lynch, D.A. Idiopathic pulmonary fibrosis: Physiologic tests, quantitative CT indexes, and CT visual scores as predictors of mortality. Radiology 2008, 246, 935-940. [CrossRef] [PubMed]

82. Maldonado, F.; Moua, T.; Rajagopalan, S.; Karwoski, R.A.; Raghunath, S.; Decker, P.A.; Hartman, T.E.; Bartholmai, B.J.; Robb, R.A.; Ryu, J.H. Automated quantification of radiological patterns predicts survival in idiopathic pulmonary fibrosis. Eur. Respir. J. 2014, 43, 204-212. [CrossRef]

83. Jacob, J.; Bartholmai, B.J.; Rajagopalan, S.; Kokosi, M.; Nair, A.; Karwoski, R.; Walsh, S.L.F.; Wells, A.U.; Hansell, D.M. Mortality prediction in idiopathic pulmonary fibrosis: Evaluation of computer-based CT analysis with conventional severity measures. Eur. Respir. J. 2017, 49, 1601011. [CrossRef]

84. Kim, H.J.; Brown, M.S.; Elashoff, R.; Li, G.; Gjertson, D.W.; Lynch, D.A.; Strollo, D.C.; Kleerup, E.; Chong, D.; Shah, S.K.; et al. Quantitative texture-based assessment of one-year changes in fibrotic reticular patterns on HRCT in scleroderma lung disease treated with oral cyclophosphamide. Eur. Radiol. 2011, 21, 2455-2465. [CrossRef]

85. Kiely, D.; Lawrie, A.; Doyle, O.; Salvatelli, V.; Daniels, F.; Drage, E.; Jenner, H.; Rigg, J.; Schmitt, C.; Samyshkin, Y.; et al. Real world data from hospital episode statistics can be used to determine patients at risk of idiopathic pulmonary arterial hypertension. Eur. Respir. Soc. 2018, 52, PA3082. Available online: http://erj.ersjournals.com/lookup/doi/10.1183/13993003.congress-2018.PA3082 (accessed on 23 March 2021). 
86. Avendi, M.R.; Kheradvar, A.; Jafarkhani, H. Automatic segmentation of the right ventricle from cardiac MRI using a learningbased approach: Automatic Segmentation Using a Learning-Based Approach. Magn. Reson. Med. 2017, 78, 2439-2448. [CrossRef] [PubMed]

87. Avendi, M.R.; Kheradvar, A.; Jafarkhani, H. A combined deep-learning and deformable-model approach to fully automatic segmentation of the left ventricle in cardiac MRI. Med. Image Anal. 2016, 30, 108-119. [CrossRef]

88. Kiely, D.G.; Levin, D.L.; Hassoun, P.M.; Ivy, D.; Jone, P.-N.; Bwika, J.; Kawut, S.M.; Lordan, J.; Lungu, A.; Mazurek, J.A.; et al. Statement on imaging and pulmonary hypertension from the Pulmonary Vascular Research Institute (PVRI). Pulm. Circ. 2019, 9, 204589401984199. [CrossRef]

89. Lungu, A.; Swift, A.; Capener, D.; Kiely, D.; Hose, R.; Wild, J. Diagnosis of pulmonary hypertension from MR image based computational models of pulmonary vascular haemodynamics and decision tree analysis. Eur. Respir. Soc. 2015, 46, PA2109. Available online: http:/ / erj.ersjournals.com/lookup/doi/10.1183/13993003.congress-2015.PA2109 (accessed on 6 December 2020).

90. Yang, M.; Ren, Y.; She, Y.; Xie, D.; Sun, X.; Shi, J.; Zhao, G.; Chen, C. Imaging phenotype using radiomics to predict dry pleural dissemination in non-small cell lung cancer. Ann. Transl. Med. 2019, 7, 259. [CrossRef]

91. Yip, S.S.F.; Aerts, H.J.W.L. Applications and limitations of radiomics. Phys. Med. Biol. 2016, 61, R150-R166. [CrossRef]

92. European Commission. Joint Research Centre. Robustness and Explainability of Artificial Intelligence: From Technical to Policy Solutions. Available online: https:/ / data.europa.eu/doi/10.2760/57493 (accessed on 2 March 2021).

93. Ibrahim, A.; Primakov, S.; Beuque, M.; Woodruff, H.C.; Halilaj, I.; Wu, G.; Refaee, T.; Granzier, R.; Widaatalla, Y.; Hustinx, R.; et al. Radiomics for precision medicine: Current challenges, future prospects, and the proposal of a new framework. Methods San Diego Calif. 2021, 188, 20-29. [CrossRef] 